\title{
A INTERACTIVIDADE COMO FOMENTADORA DA LUDICIDADE: EM BUSCA DE CAMINHOS E SENTIDOS NA EDUCAÇÃO INFANTIL
}

Denise Watanabe, Tony Aparecido Moreira, José Milton de Lima, Márcia Regina Canhoto de Lima.

Universidade Estadual Paulista - UNESP, Departamentos: Educação e Educação Física, Presidente Prudente, SP. Email: de.wtnb@gmail.com. Agência Financiadora: CAPES.

\section{RESUMO}

Este artigo apresenta resultados de uma pesquisa de mestrado realizada em uma escola de Educação Infantil situada em um bairro localizado na periferia de um município do Oeste Paulista, ao constatar que havia uma carência em compreender e em integrar a interactividade como elemento fomentador da ludicidade. A partir desse fato, os objetivos que nortearam a dissertação de mestrado foram aprofundar os conhecimentos e a compreensão acerca das relações sociais (interactividade) entre adultos/crianças, crianças/adultos e crianças/pares infantis, com vistas a fomentar a ludicidade, por meio de atividades e de recursos lúdicos que fossem diversificados e significativos às crianças. Fundamentada na Sociologia da Infância, na pesquisa qualitativa e na metodologia da investigação-ação, recorreu-se a diálogos com crianças e com as professoras; as observações; as fotos; as anotações no diário de campo. Como resultados, a partir dos estreitamentos dos laços interpessoais, destacaram-se: avanços na produção de uma pesquisa realizada com as crianças e não somente sobre elas; a ênfase na interactividade, que por meio dos relatos das crianças era visto como motivo de "alegria" por elas ou pelos personagens das histórias; e o desejo e a solicitação de crianças de outras seriações para que a pesquisa/brincadeiras se expandisse e contemplasse também o Ensino Fundamental. A interactividade e a ludicidade fundamentam os eixos estruturadores das culturas infantis e os eixos das Diretrizes Curriculares Nacionais da Educação Infantil (DCNEI) e estão presentes em diversos documentos legais. Mais do que direito, constituem especificidades infantis e devem, portanto, ser compreendidos e valorizados. Destacamos que a interactividade e ludicidade se complementam, visto que a brincadeira não é inata, mas elemento cultural que precisa ser ensinado/aprendido/recriado.

Palavras-chave: Educação, Sociologia da Infância, Culturas Infantis.

\section{THE INTERACTIVITY AS NURTURING OF PLAYFULNESS: IN SEARCH OF PATHS AND DIRECTIONS IN EARLY CHILDHOOD EDUCATION.}

\begin{abstract}
This paper presents results of a Masters research performed in a children's education school located in a neighborhood located on the outskirts of a city in the West, to find that there was a need to understand and integrate interactivity as spurred playfulness. From that fact, the objectives that guided the dissertation were deepening the knowledge and understanding of social relations (interactivity) among adults/children, children/adults and children/infant pairs, with a view to promote playfulness, through activities and recreational resources that were diverse and meaningful to children. Based on the Sociology of childhood, in qualitative research and methodology of action research, dialogue was used with children and teachers; the observations; the photos; the notes in the field journal. As a result, from tapers of interpersonal ties, stood out: advances in the production of a research conducted with children and not only about them; the emphasis on interactivity, that through the accounts of children was seen as a cause for "joy" by them or by the characters in the stories; and the desire and the other children sequence request for research/games to expand and failed to take into account also the elementary school. The interactivity and playfulness are based structuring axes of the cultures and the axes of the national early childhood education curriculum guidelines (DCNEI) and are present in several legal documents. More than law, constitute children's specificities and should, therefore, be understood and valued. We highlight that the interactivity and playfulness complement each other, since the joke is not innate, but cultural element that needs to be taught/learned/recreated.
\end{abstract}

Keywords: Education, Sociology of childhood, children's Cultures. 


\section{INTRODUÇÃO}

A Educação Infantil - primeira etapa da educação básica (LDB, Lei no 9.394/96) - é um período de transição, ao qual a criança deixa o ambiente exclusivamente familiar para ingressar em um espaço institucionalizado de ensino (creche ou pré-escola), ampliando o contato com um número significativo de pessoas, de culturas, de gostos, de modos de ser, de pensar e de agir. Como destaca o RCNEI (1998, p. 13), o ingresso:

[...] na instituição de educação infantil pode alargar o universo inicial das crianças, em vista da possibilidade de conviverem com outras crianças e com adultos de origens e hábitos culturais diversos, de aprender novas brincadeiras, de adquirir conhecimentos sobre realidades distantes.

Diversas linguagens devem ser contempladas: oral, escrita, movimento, música, faz de conta (imaginação), interações e brincadeiras (RCNEI, 1998). As interações são imprescindíveis - visto que são nessas interações que as crianças estabelecem desde cedo com pessoas próximas e com o contexto circundante, que elas:

[...] revelam seu esforço para compreender o mundo em que vivem, as relações contraditórias que presenciam e, por meio das brincadeiras, explicitam as condições de vida a que estão submetidas e seus anseios e desejos. No processo de construção do conhecimento, as crianças se utilizam das mais diferentes linguagens e exercem a capacidade que possuem de terem idéias e hipóteses originais sobre aquilo que buscam desvendar. Nessa perspectiva as crianças constroem o conhecimento a partir das interações que estabelecem com as outras pessoas e com o meio em que vivem. $\mathrm{O}$ conhecimento não se constitui em cópia da realidade, mas sim, fruto de um intenso trabalho de criação, significação e ressignificação. (Brasil. Ministério da Educação e do Desporto, 1998, v.1, p. 2122).

Brincar - mais do que prioridade - constitui um direito amparado pela Declaração Universal dos Direitos da Criança de (1959); pela Constituição Federal de 1988 (BRASIL. Constituição, 1988); pelo Estatuto da Criança e do Adolescente - ECA de 1990 (BRASIL, 2014); pelas Diretrizes Curriculares Nacionais da Educação Infantil DCNEI de 2010 (BRASIL. Ministério da Educação, 2010); pelo Referencial Curricular Nacional da Educação Infantil - RCNEI (BRASIL. Ministério da Educação e do Desporto, 1998).

Conforme o Princípio VII - "Direito à educação gratuita e ao lazer infantil" da Declaração Universal dos Direitos da Criança (1959), a criança "[...] deve desfrutar plenamente de jogos e brincadeiras os quais deverão estar dirigidos para educação; a sociedade e as autoridades públicas se esforçarão para promover o exercício deste direito (UNICEF)".

No capítulo VII, Art. 227 (p. 82) da Constituição da República Federativa do Brasil de 1988, intitulado "Da Família, da Criança, do Adolescente, do Jovem e do Idoso", a criança tem direito ao lazer, sendo dever:

[...] da família, da sociedade e do Estado assegurar à criança, ao adolescente e ao jovem, com absoluta prioridade, o direito à vida, à saúde, à alimentação, à educação, ao lazer, à profissionalização, à cultura, à dignidade, ao respeito, à liberdade e à convivência familiar e comunitária, além de colocá-los a salvo de toda forma de negligência, discriminação, exploração, violência, crueldade e opressão. (EC no 65/2010)

Conforme o art. 16 do capítulo II - "Do direito à liberdade, ao respeito e à dignidade", do Estatuto da Criança e do Adolescente - ECA (BRASIL, 2014), o direito infantil à liberdade compreende diversos aspectos, dentre eles "brincar, praticar esportes e divertir-se (item IV)".

Para as DCNEI (BRASIL. Ministério da Educação, 2010, p. 12), as brincadeiras ocorrem 
por meio das interações e relações que as crianças estabelecem no dia a dia. Conforme esse documento, a criança é:

Sujeito histórico e de direitos que, nas interações, relações e práticas cotidianas que vivencia, constrói sua identidade pessoal e coletiva, brinca, imagina, fantasia, deseja, aprende, observa, experimenta, narra, questiona e constrói sentidos sobre a natureza e a sociedade, produzindo cultura.

As DCNEI (BRASIL. Ministério da Educação, 2010, p. 18) destacam que os objetivos da Proposta Pedagógica das escolas de Educação Infantil devem garantir as interações e brincadeiras, possibilitando o acesso da criança a:

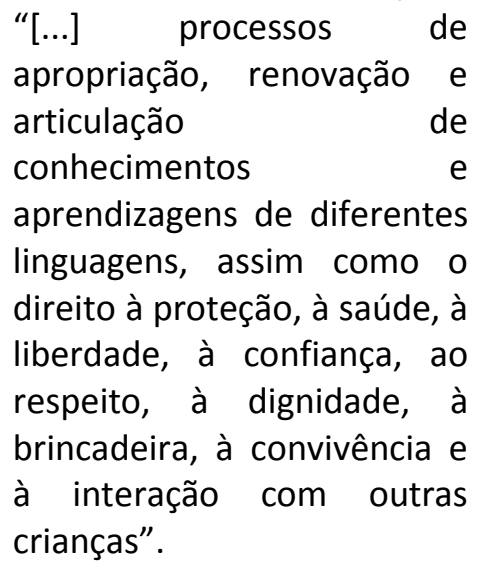

Ainda conforme as DCNEI, as "práticas pedagógicas que compõem a proposta curricular da Educação Infantil" devem ter como eixos norteadores "[...] as interações e a brincadeira" (BRASIL. Ministério da Educação, 2010, p. 25).

No entanto, apesar de a interactividade e a ludicidade perpassarem diversos documentos legais e mostrarem-se imprescindíveis às crianças, elas ainda não são devidamente valorizadas e contempladas no contexto da Educação Infantil, devido muitas práticas e concepções ainda se pautarem em vertentes tradicionais de ensino que desconsideram as especificidades infantis e que naturalizam as brincadeiras, como se elas ocorressem de forma natural ou espontânea.

O Manual de orientação pedagógica "Brinquedos e brincadeiras de creches" - pautado nas DCNEI - propõe diversas ações voltadas às crianças de 0 a 3 anos e 11 meses. Conforme o manual, "[...] a pouca qualidade ainda presente na educação infantil pode estar relacionada à concepção equivocada de que o brincar depende apenas da criança, não demanda suporte do adulto, observação, registro nem planejamento" (BRASIL. Ministério da Educação, 2012, p. 11-12), fato que precisa de desconstrução, visto que a criança,

[...] não nasce sabendo brincar. Ao ser educada, a criança deve entrar em um ambiente organizado para recebê-la, relacionar-se com as pessoas (professoras, pais e outras crianças), escolher os brinquedos, descobrir os usos dos materiais e contar com a mediação do adulto ou de outra criança para aprender novas brincadeiras e suas regras. Depois que aprende, a criança reproduz ou recria novas brincadeiras e assim vai garantindo a ampliação de suas experiências. É nesse processo que vai experimentando ler o mundo para explorá-lo: vendo, falando, movimentando-se, fazendo gestos, desenhos, marcas, encantando-se com suas novas descobertas. (BRASIL. Ministério da Educação, 2012, p. 11-12)

O RCNEI (Brasil. Ministério da Educação e do Desporto, 1998, v.1, p. 28) destaca que é o adulto - na figura do professor - que na educação infantil, deve ajudar a estruturar as brincadeiras "[...] na vida das crianças. Consequentemente é ele que organiza sua base estrutural, por meio da oferta de determinados objetos, fantasias, brinquedos ou jogos, da delimitação e arranjo dos espaços e do tempo para brincar". O RCNEI destaca ainda o papel da "intervenção intencional" com base na observação das brincadeiras infantil e na oferta de,

[...] material adequado, assim como um espaço estruturado para brincar permite 0 enriquecimento das competências imaginativas, criativas e organizacionais infantis. Cabe ao professor organizar 
situações para que as brincadeiras ocorram de maneira diversificada para propiciar às crianças a possibilidade de escolherem os temas, papéis, objetos e companheiros com quem brincar ou os jogos de regras e de construção, e assim elaborarem de forma pessoal e independente suas emoções, sentimentos, conhecimentos e regras sociais (Brasil. Ministério da Educação e do Desporto, 1998, v.1, p. 29).

As brincadeiras podem auxiliar no pleno desenvolvimento infantil, nas capacidades como,

[...] a atenção, a imitação, a memória, a imaginação. Amadurecem também algumas capacidades de socialização, por meio da interação e da utilização e experimentação de regras e papéis sociais. $\mathrm{Na}$ brincadeira, vivenciam concretamente a elaboração e negociação de regras de convivência, assim como a elaboração de um sistema de representação dos diversos sentimentos, das emoções e das construções humanas RCNEl (Brasil. Ministério da Educação e do Desporto, 1998, v. 2, p 22-23).

Portanto, as interações entre adultos e crianças de idades diferentes "[...] as brincadeiras nas suas mais diferentes formas, a exploração do espaço, o contato com a natureza", que "[...] se constituem em experiências necessárias para o desenvolvimento e aprendizagem infantis (Brasil. Ministério da Educação e do Desporto, 1998, v. 3, p. 181)".

A interactividade e a ludicidade, além de integram os eixos das Diretrizes Curriculares Nacionais da Educação Infantil - DCNEI (BRASIL. Ministério da Educação, 2010, p. 25) constituemse eixos estruturadores das culturas da infância. Para Sarmento (2004), os quatro eixos estruturadores das culturas da infância constituem-se em: ludicidade (brincadeiras), fantasia do real (imaginação), interactividade (relações sociais) e reiteração (tempo sincrônico ou diacrônico).

A interactividade constitui base das culturas da infância. Essas culturas expressam-se pelas "[...] dimensões relacionais" e "[...] constituem-se nas interações de pares e das crianças com os adultos, estruturando-se nessas relações formas e conteúdos representacionais distintos" (SARMENTO, 2004, p. 12).

Cabe, portanto,

ao professor/educador/pesquisador no contexto da Educação Infantil compreender a importância da mediação, com vistas a promover uma relação mais horizontal e menos impositiva; estabelecer um processo de comunicação e interlocução ao invés de transmissão e controle, fomentar ações e práticas repletas de intencionalidade e de significado que valorizem a ludicidade; possibilitar a cultura de pares e ampliar/estimular a cultura infantil, compreendendo as crianças como (re) produtora de cultura, fonte do novo.

Oferecer às crianças "[...] a possibilidade de entendimento, de domínio e de realização de suas próprias brincadeiras, pois é por meio das experiências acumuladas que a criança constrói e amplia sua cultura lúdica", criar "[...] tempos e espaços nas instituições de Educação Infantil para que o brincar aconteça, pois a brincadeira é cultural e socialmente transmitida e aprendida, e não uma atividade natural, que aparece espontaneamente" (LIMA; LIMA, 2013 p. 213).

Diante das considerações acerca da interactividade e da interactividade, este artigo apresenta resultados da pesquisa de mestrado intitulada "A interactividade como fomentadora da ludicidade: tudo fica "típico" quando as crianças brincam na Educação Infantil". Financiada pela Coordenação de Aperfeiçoamento de Pessoal de Nível Superior CAPES, segue produtivamente em uma escola de Educação Infantil de um bairro periférico localizado em um Município do Oeste Paulista.

$\mathrm{O}$ interesse pela temática emergiu a partir de intervenções em um projeto de

\footnotetext{
1 "Típico" é utilizado no título da pesquisa como um "trocadilho" para o conceito de "adulto atípico", de Corsaro (2011), que se refere a um adulto que, por respeitar as crianças, por entender suas especificidades e necessidades, por adentrar o mundo infantil e adotar meios para melhor compreendê-lo, passa a ser visto como "atípico" pelas crianças, algo que não é comum ou recorrente a todos os adultos. Subentende-se, dessa forma, que as brincadeiras deveriam ser "típicas" na Educação Infantil, visto que além de linguagem e elemento cultural humano, constituem aquilo que a criança faz de mais sério. As interações e as brincadeiras também integram os eixos estruturadores das culturas da infância e eixos das DCNEI - bases curriculares da Educação Infantil.
} 
extensão, numa parceria entre uma escola de Educação Infantil, a prefeitura Municipal e a Faculdade de Ciências e Tecnologia - FCT/UNESP - Campus de Presidente Prudente. No decorrer desse projeto, originou-se a Iniciação Científica (IC) e o objeto de investigação do mestrado, ao constatar que havia uma carência em compreender e integrar a interactividade como principal elemento fomentador da ludicidade.

A partir desse fato, fundamentada na Sociologia da Infância, na pesquisa de natureza qualitativa e na metodologia da investigaçãoação, recorreu-se a observações; a anotações no diário de campo; aos diálogos constantes com as crianças, com as professoras e, posteriormente, com alguns familiares ${ }^{2}$; além do uso de fotos.

Como recursos metodológicos, utilizou-se de brincadeiras, de histórias, de fantoches, de músicas, de brinquedos (tradicionais ou confeccionados com materiais recicláveis e/ou acessíveis, com a ajuda das crianças), entre outras atividades.

Como resultados, destacam-se:

- Avanços na produção e pesquisa realizada com as crianças e não somente sobre elas;

- A ênfase na interactividade, que por meio dos relatos das crianças era visto como motivo de "alegria" por elas ou pelos personagens das histórias;

- E o desejo e a solicitação de crianças de outras seriações ${ }^{3}$ para que a pesquisa/brincadeiras se expandisse e contemplasse também 0 Ensino Fundamental.

Compreende-se que a criança "[...] constrói e amplia sua cultura lúdica", por meio das "[...] experiências acumuladas" e da "[...] possibilidade de entendimento, de domínio e de realização de suas próprias brincadeiras" (LIMA; LIMA, 2013 p. 213), o que requer tempos, espaços, recursos e interações que fomentem a ludicidade. A partir desse fato, os objetivos que nortearam a dissertação de mestrado foram aprofundar os conhecimentos e a compreensão

\footnotetext{
${ }^{2}$ Ao perceber que, muitos pais cobravam e priorizavam o ensino das linguagens orais e escritas naquele espaço de Educação Infantil e que as brincadeiras eram secundarizadas, surgiu à necessidade de dialogar com alguns responsáveis das crianças participantes na pesquisa, para compreender suas concepções acerca das brincadeiras e referentes à pesquisa.

${ }^{3}$ Crianças participantes da pesquisa em anos anteriores, ou, ainda, que observavam e acompanhavam a pesquisa de longe, sem nunca ter participado de nenhuma atividade lúdica proposta pela pesquisadora.
}

acerca das relações sociais (interactividade) entre adultos/crianças, crianças/adultos e crianças/pares infantis, com vistas a fomentar a ludicidade, por meio de atividades e de recursos lúdicos que fossem diversificados e significativos às crianças, visto que a brincadeira não é inata, mas elemento cultural que precisa ser ensinado, aprendido, (re) criado.

\section{METODOLOGIA}

Essa pesquisa fundamentou-se teoricamente nos estudos da Sociologia da Infância, vertente oriunda a partir da década de 1980 no contexto Europeu, cujos movimentos e debates de pesquisadores se voltaram à criança e à infância. Conforme a Sociologia da Infância, as crianças deveriam ser compreendidas como sujeitos ativos, atores sociais, (re) produtores de cultura, com necessidades, especificidades, desejos e anseios. A infância - construção social, histórica e cultural - emergiu na Modernidade, com a ênfase no "sentimento de infância", descrito por Ariès.

Além da Sociologia da Infância, a pesquisa fundamentou-se em alguns documentos importantes para a área, como a Declaração Universal dos Direitos da Criança de 1959; a Constituição Federal de 1988; o Estatuto da Criança e do Adolescente - ECA; as Diretrizes Curriculares Nacionais da Educação Infantil DCNEI; o Referencial Curricular Nacional da Educação Infantil - RCNEI (BRASIL. Ministério da Educação e do Desporto, 1998).

De natureza qualitativa e embasada na metodologia da investigação-ação, buscou-se uma pesquisa realizada com as crianças e não somente sobre elas, com vistas a valorizar a participação, a escuta, as expressões, os desejos e os pensamentos infantis. Para Muller (2010, p. 67), todo pesquisador deveria "[...] abrir mão de qualquer possibilidade de juízos e de valores que possam corromper a tonalidade do que é dito pela criança, não cedendo lugar à tentação de querer ouvir o que se pretende ouvir".

De caráter qualitativo, consideramos aspectos observáveis que permitiram reflexões, diálogos e mudanças processuais com os envolvidos no contexto. Os dados quantitativos (numéricos), portanto, não foram evidenciados, visto que o objetivo era valorizar os avanços e conquistas qualitativas, que entendemos como processuais e gradativas. Conforme Silva e Menezes (2005, p. 20): 
[...] há uma relação dinâmica entre o mundo real e o sujeito, isto é, um vínculo indissociável entre o mundo objetivo e a subjetividade do sujeito que não pode ser traduzido em números. A interpretação dos fenômenos e a atribuição de significados são básicas no processo de pesquisa qualitativa. Não requer o uso de métodos e técnicas estatísticas. 0 ambiente natural é a fonte direta para coleta de dados e o pesquisador é o instrumento-chave. É descritiva. Os pesquisadores tendem a analisar seus dados indutivamente. 0 processo e seu significado são os focos principais de abordagem.

A investigação-ação se ajustou adequadamente às necessidades da pesquisa. Ela permitiu suscitar análises, reflexões e ações empíricas, com vistas a conhecer melhor o contexto, dialogar com os envolvidos na pesquisa e buscar os melhores caminhos a seguir. Para Contreras-Domingos (1994 p. 14) a investigação ação:

[...] es uma forma de entender la práctica docente según la cual intentamos meiorar-la

sistematicamente, buscando para ello entender mejor caules son los contextos $y$ condicionantes de la misma. No es sólo uma ayuda para resolver los problemas de la práctica, sino que es um processo para, problematizar la práctica, es decir, para descobrir la naturaliza problemática de la ensenanza y para, problématizándola, reorientar el sentido de la misma, así como nuestra valoración de lo que ésta debiera ser, a lo que debiera aspirar.
Realizada uma vez por semana, contemplava cinquenta crianças (de quatro a cinco anos e 11 meses) de uma EMEIF de um bairro periférico, localizada em um Município do Oeste Paulista.

A pesquisa seguia um roteiro flexível (que considerava as necessidades infantis) com atividades desenvolvidas em dois momentos:

- Na sala, ao dialogar com as crianças e com as professoras sobre as rotinas, as atividades que fizeram durante a semana e, posteriormente, apresentando a temática/história,

- Na quadra ou pátio, propondo a (s) brincadeira(s), observando a prática e também ouvindo as crianças em suas dificuldades, avanços, divertimentos, anseios.

Ao final, buscava-se obter uma devolutiva do que foi realizado, do que acharam ou do gostariam para a próxima semana.

Como recursos metodológicos, recorreuse ao uso de atividades e de recursos lúdicos (que fossem significativos e diversificados às crianças), como histórias tradicionais ou criadas - conforme as falas e as necessidades infantis; brincadeiras; fantoches; músicas; brinquedos (construídos com as crianças, utilizando materiais acessíveis e/ou recicláveis, como jornais, barbantes, bexigas, TNT, EVA, etc.).

Os brinquedos são objetivos privilegiados da educação infantil. Conforme o RCNEI (Brasil. Ministério da Educação e do Desporto, 1998, v.1, p. 71) eles constituem-se, entre outros, em:

[...] objetos privilegiados da educação das crianças. São objetos que dão suporte ao brincar e podem ser das mais diversas origens materiais, formas, texturas, tamanho e cor. Podem ser comprados ou fabricados pelos professores e pelas próprias crianças; podem também ter vida curta, quando inventados e confeccionados pelas crianças em determinada brincadeira e durar várias gerações, quando transmitidos de pai para filho. Nessa perspectiva, as instituições devem integrá-los ao acervo de materiais existentes nas 
salas, prevendo critérios de escolha, seleção e aquisição de acordo com a faixa etária atendida e os diferentes projetos desenvolvidos na instituição.

O RCNEI também destaca a importância da diversidade de experiências para que a capacidade de criar das crianças ocorra. Para o RCNEI (Brasil. Ministério da Educação e do Desporto, 1998, v.1, p. 27) “[...] é imprescindível que haja riqueza e diversidade nas experiências que Ihes são oferecidas nas instituições, sejam elas mais voltadas às brincadeiras ou às aprendizagens que ocorrem por meio de uma intervenção direta".

Para a coleta e a sistematização dos dados, recorreu-se às observações e às anotações no diário de campo (referentes às brincadeiras e às interações); às fotos; aos diálogos recorrentes com as professoras e as crianças.

Protocolo de aprovação pelo Comitê de Ética em Pesquisa (CEP) dessa pesquisa: 1.499.306.

\section{RESULTADOS}

Como resultados da pesquisa de mestrado, a partir dos estreitamentos dos laços interpessoais, destacaram-se: avanços na produção de uma pesquisa realizada com as crianças e não somente sobre elas; a ênfase na interactividade, que por meio das amizades e dos relatos das crianças era visto como motivo de "alegria" por elas ou pelos personagens das histórias; e o desejo e a solicitação de crianças de outras seriações para que a pesquisa/brincadeiras se expandisse e contemplasse também o Ensino Fundamental.

Muitos resultados e dados alcançados só foram possíveis devido à pesquisadora se colocar numa relação horizontal, de abertura e de escuta às crianças, permitindo que durante os momentos de observação elas pudessem dialogar e expressar seus desejos, anseios, sonhos, medos, contentamentos.

A pesquisa foi construída com a colaboração infantil e a participação delas foi imprescindível. Elas mostraram que, quando buscamos escutá-las, enxergá-las, compreendelas e valorizá-las, elas têm muito a nos ensinar visto que elas são fonte do novo!

\section{DISCUSSÕES}

As aulas na escola de Educação Infantil iniciaram em fevereiro de 2016, mas as atividades da pesquisa de mestrado iniciaram somente abril, visto que era necessário esperar a aprovação do Comitê de Ética em Pesquisa. Com "atraso", algumas crianças que já participaram da pesquisa em anos anteriores ${ }^{4}$ lamentaram:

Ana : - "A gente tava ${ }^{6}$ esperando esse dia faz tempo".

Pesquisadora: -"Por quê?".

Ana: -"Porque a gente tava com saudade". questionou:

Em outro momento, outra criança Joana: -"Por que você demorou pra chegar na nossa escola?".

No desenrolar do diálogo, ela insistiu:

Joana: -"É agora que você vai dar aula pra gente? Você vai ali naquela quadra?".

Pesquisadora: -“Hoje está chovendo" (as brincadeiras seriam realizadas no pátio).

A criança foi enfática:

Joana: -"Mas e aquela outra quadra7?" (DIÁRIO DE CAMPO, 2016).

No decorrer da pesquisa, notou-se o desejo e a solicitação de diversas crianças de outras seriações ${ }^{8}$ para que a pesquisa se expandisse e contemplasse também o Ensino Fundamental. Tais questões eram recorrentes:

Júnior: -"Por que você não tá dando aula pra gente?".

Pesquisadora: -“Porque é só para o infantil, lembra? Você está com saudades da gente?".

Júnior: -"Sim, das brincadeiras" (DIÁRIO DE CAMPO, 2016).

Em outro dia de pesquisa, uma criança que não costuma ver com frequência, se aproximou e expressou o desejo em participar da pesquisa:

\footnotetext{
${ }^{4}$ A pesquisa de Iniciação Científica teve início nessa mesma escola em 2013. Posteriormente, com o ingresso da bolsita no mestrado no ano de 2015, outra bolsista assumiu as atividades, tendo o acompanhamento e o respaldo da ex-bolsista.

5 Para resguardar e preservar a identidades de todos os participantes da pesquisa (crianças e professoras), todos os nomes utilizados nesse artigo/pesquisa são fictícios.

${ }^{6}$ Por respeitar as especificidades infantis e as formas de a criança se expressar, agir e atuar no mundo (muitas vezes divergentes dos adultos), todas as falas foram transcritas fidedignamente como foram verbalizadas pelas crianças, sem alterações ou correções de português.

${ }^{7}$ A escola possuía duas quadras, uma coberta e outra ao ar livre. No entanto, na maioria das vezes, a quadra coberta era utilizada pelo professor de Educação Física da escola.

${ }^{8}$ Crianças participantes da pesquisa em anos anteriores, ou, ainda, que apenas observavam e acompanhavam de longe, sem nunca ter participado da pesquisa.
} 
Bia: -“Oiiii! Eu lembro de você. Você já deu aula para mim".

Bia: -"Por que você nunca mais deu aula para gente?" infantil”.

Pesquisadora: -"Porque é só para o gente".

Bia: -"Ah, mas você podia dar aula pra

Pesquisadora: -"Em qual ano você está"?

Bia: -"No terceiro ano" (DIÁRIO DE CAMPO, 2016).

Em outros momentos durante o recreio, algumas crianças, ao abraçarem a pesquisadora, questionavam:

Fabio: -"Prô, porque você não dá mais brincadeiras pra gente?" (DIÁRIO DE CAMPO, 2016).

Outra criança que estava no primeiro ano do Ensino Fundamental também ressaltou:

Sara: -"Prô, você lembra do pintinho, aquele que tem fiozinho, corda de crochê, daquele amarelinho?".

Pesquisadora: -“Você tem ainda?".

Sara: -"Tenho!".

Pesquisadora: -"E você tem saudade das brincadeiras?".

Sara: -"Sim, eu queria que tivesse as brincadeiras também no primeiro ano, ia ser bem legal".

Pesquisadora: -"E por que ia ser legal?".

Sara: -"Porque suas aulas são super legais" (DIÁRIO DE CAMPO, 2016).

No decorrer do ano, diversas crianças de outras seriações se aproximavam para perguntar: -"por que você não dá brincadeira pra nós?"; "Prô, você não vai dar brincadeira pra gente hoje?"; - “Prô, por que você não dá aula pra gente também?" (DIÁRIO DE CAMPO, 2016).

As brincadeiras também eram lembradas pelas crianças do Ensino Fundamental (participantes da pesquisa em anos anteriores):

Luis: -"Cobra, cavalinho, aquele cavalo que a gente senta em cima, super-herói, do limão, aquele que a gente pula, teve de pipoca, do balão, caça ao tesouro, nos tirávamos foto, nós dançamos música do pônei e do dinossauro" (DIÁRIO DE CAMPO, 2016).

Muitas vezes, as crianças associavam as amizades ou o fato de ter amigos, como motivo de felicidade/alegria para elas ou para os personagens das histórias apresentadas pela pesquisadora. Em uma das histórias, o cavalo tinha um "sonho". As crianças deveriam adivinhar qual era. Muitas delas, então, expressaram diversos "sonhos", entre eles, "ter amigos":

Crianças: Voar, andar, beber água, ter chifre, estar no mato, ser touro, destruir o planeta, um barco, andar de helicóptero, a gente quer montar no cavalo, ser feliz, morar numa casa, ser mulher, viver, que uma gente montasse nele, andar no mato, estudar, ter amigos, andar de trenó, ser feliz e ter amigo, ser livre, ter bastante amigo num lugar bem bom pra ele, comer capim, brincar, ter um dono, casar, nadar no mar, fazer muitos amigos, comer, andar de trem (DIÁRIO DE CAMPO, 2016).

A interactividade também era expressa pela ausência de amizades - associada como motivo de "tristeza" dos personagens. Em outra história, havia uma serpente que estava triste. Antes de esclarecer que a tristeza era resultante do fato de "ela ter perdido um pedacinho de seu rabo", questionou-se às crianças o que elas imaginavam ser o motivo pelo qual a cobra estava triste.

João respondeu: - "A cobra tá triste porque ninguém gosta dela, ninguém quer ser amigo dela" (DIÁRIO DE CAMPO, 2016).

Em outros momentos e histórias, com outros personagens, a resposta de que "estava triste porque era sozinho ou porque não tinha com quem brincar" era frequente:

Caio: -"O dinossauro tava triste porque ninguém queria brincar com ele, porque tinham medo dele". Nessa mesma brincadeira com o dinossauro, Igor respondeu que o dinossauro estava bravo. Ao indagá-lo: -"Por que ele estava bravo?" Igor respondeu: -"porque ele não tinha amigos" (DIÁRIO DE CAMPO, 2016).

Na história do pônei (que havia perdido a sua cauda) novamente uma resposta referente aos motivos da tristeza, associada à falta de amigos:

Iza: -"porque ele não tinha amiguinho".

Outra criança, de outra sala, também respondeu: -“Não tinha amigo!" (DIÁRIO DE CAMPO, 2016).

$\mathrm{Na}$ brincadeira em que as crianças deveriam passar por vários barbantes entrelaçados, que imitavam as teias de uma aranha (enroscada entre os fios, com a possibilidade de cair) duas crianças dialogam:

Vítor: -"A aranha tá chorando";

Márcio: -"A aranha tá chorando porque ninguém gosta dela" (DIÁRIO DE CAMPO, 2016).

Com as respostas das crianças foi possível perceber a importância da interactividade, 
principalmente da amizade com os pares e também com os adultos. No decorrer da pesquisa, algumas crianças buscavam amparo devido às questões de amizade para solucionar conflitos:

Paulo: -"Prô, ninguém quer ser meu amigo. Eu pedi desculpa duas vezes pra ele e ele nem ligou". Ao ver que a criança chorava, o amigo se aproximou, e ambos se abraçaram (DIÁRIO DE CAMPO, 2016).

No decorrer da pesquisa, algumas crianças relatavam sobre a "falta de amigos". comigo".

Ana: -"Prô, ninguém quer brincar

Maria: -"Eu não tenho amigos".

Além das amizades, os namoros também faziam parte do cotidiano escolar. Algumas crianças do infantil relatavam:

Edu: -"Eu não sou mais namorado da Maria. Eu sou só amigo".

Rogério: -"Você e a Maria são namorado"!

Edu bate levemente em Rogério, com "cara feia", numa tentativa de repreender o amigo (DIÁRIO DE CAMPO, 2016).

$\mathrm{Na}$ primeira atividade, após as férias escolares de junho, contou-se a história de um peixe com um barco dentro da boca. Após o termino da história, as crianças começaram a expressar suas impressões:

Paula: -"Ele gostou do barco e está apaixonado".

Mirian: -"Peixe do amor".

Lucas: -"Prô, tira uma foto? Meu tubarão/peixe está comendo o meu braço.

Pequisadora: -"Espera um pouquinho que o celular desligou".

Lucas: -"Vai logo que tá doendo. Come a mão da prô (pesquisadora)".

Outras crianças também relatavam sobre seus "relacionamentos":

Jane: -"Tem vez que a gente brinca e a gente briga. A gente faz as pazes de novo. Ele gosta de mim e eu gosto dele".

Pesquisadora: -"Ele é legal então?".

Jane: -"Ele é muito engraçado e o meu primo é muito engraçado, ele é engraçadinho. Ele gosta de brincar" (DIÁRIO DE CAMPO, 2016).

Em outro momento, mais um diálogo sobre amizade:

Carla: -"A Bia não é sua amiga”.

Bia: -"Eu sou” (DIÁRIO DE CAMPO, 2016).

Três crianças (participantes da pesquisa) brincavam juntas. Uma delas iniciou a conversa:
Enzo: -"porque vocês pintam tudo junto?".

Luan: -"Porque a gente quer copiar".

Lucas: -"Porque a gente é amigo" (DIÁRIO DE CAMPO, 2016).

Em outra atividade que era necessário pintar o desenho para depois utilizá-lo na história, um grupo de crianças estava aglomerado em uma única carteira.

Pesquisadora: -"vocês estão pintando juntos por quê?".

Jonas ("dono" da carteira) responde: "Porque eles gostam de mim" (DIÁRIO DE CAMPO, 2016).

Os brinquedos de materiais recicláveis e/ou acessíveis - construídos juntos com as crianças - eram dados a elas para levá-los para suas casas. Lá era possível (re) iniciar a brincadeira ou (re) inventá-la:

Gabi: -"Prô, você deu o cavalinho?".

Pesquisadora: -"Qual? Aquele de jornal?".

Gabi: -"Não prô, aquele pequenininho. É que o meu primo João, do infantil II tava brincando com o cavalinho".

Pesquisadora: -"Aqui (na escola) ou em casa?".

Gabi: -"Em casa” (DIÁRIO DE CAMPO, 2016).

No decorrer da pesquisa foi possível compreender a importância da interactividade e da ludicidade para as crianças, que se expressaram criativamente e de maneira diferente dos adultos, vivenciando suas culturas infantis, ao brincar, ao imaginar, ao interagir com os pares (e com os adultos), ao (re) inventar e (re) iniciar a brincadeira em seu tempo.

Ao perguntar às crianças se elas sabiam o que era "imaginar?" E explicar que era preciso "fechar os olhos e pensar"...

Uma delas, diferentemente do adulto, por fim respondeu:

Pedro: -"Eu não penso, eu sonho" (DIÁRIO DE CAMPO, 2016).

\section{CONCLUSÃO}

Essa pesquisa de mestrado almejou, portanto, aprofundar os conhecimentos e a compreensão acerca das relações sociais (interactividade) entre adultos/crianças, crianças/adultos e crianças/pares infantis, com vistas a fomentar a ludicidade, por meio de atividades e de recursos lúdicos que fossem diversificados e significativos às crianças. 
A interactividade e a ludicidade fundamentam os eixos estruturadores das culturas infantis e os eixos das Diretrizes Curriculares Nacionais da Educação Infantil (DCNEI) e estão presentes em diversos documentos legais. Mais do que direito, constituem especificidades infantis e devem, portanto, ser compreendidos e valorizados. Destacamos que a interactividade e ludicidade se complementam, visto que a brincadeira não é inata, mas elemento cultural que precisa ser ensinado/aprendido/recriado.

As brincadeiras fazem parte do cotidiano, fazem parte da vida da criança. Brincar é próprio do homem, todavia, para a criança é um eixo caracterizador das suas culturas. É um direito, uma linguagem, uma forma de expressão, um recurso pedagógico, atividade principal, um elemento que auxilia a imaginação, uma produção humana, social, histórica e cultural.

O papel do professor/educador/pesquisador deve ser o de priorizar relações mais horizontais e menos impositivas; criar e proporcionar ações e práticas repletas de intencionalidade e de significado, com vistas a fomentar a participação e as falas das crianças e compreender as culturas infantis.

Para as crianças, pode-se aprender - por meio da interactividade - a: criar estratégias e meios para burlar/transgredir as regras e normas adultas; a observar e a pensar em formas para adentrar as brincadeiras e/ou fazer amizades (elas, insclusive, expressaram a importância de se "ter amigos"); a expressar sentimentos, desejos e (des) contentamentos. Para as crianças "ter amigos" e "ser feliz" podem ser tratados como sinônimos ou como "sonho". Nós devemos aprender com elas!

\section{REFERÊNCIAS:}

BRASIL. Constituição (1988). Constituição da

República Federativa do Brasil: texto

constitucional promulgado em 5 de outubro de 1988, com as alterações adotadas pelas Emendas constitucionais nos 1/1992 a 91/2016, pelo Decreto legislativo no 186/2008 e pelas Emendas constitucionais de revisão nos 1 a 6/1994. 49. ed. Brasília : Câmara dos Deputados, Edições Câmara, 2016. (Série textos básicos; n. 140). BRASIL. Ministério da Educação. Secretaria de Educação Básica. Diretrizes curriculares nacionais para a educação infantil. Brasília: MEC/SEB, 2010. 36 p.
BRASIL. Ministério da Educação. Secretaria de Educação Básica. Brinquedos e brincadeiras de creches: manual de orientação pedagógica.

Brasília: MEC/SEB, 2012. 158 p.

BRASIL. Estatuto da criança e do adolescente e legislação correlata: Lei n. 8.069, de 13 de julho de 1990, e legislação correlata. 12. Ed. Brasília: Câmara dos Deputados, Edições Câmara, 2014. 241 p. (Série legislação; n. 122). Disponível em: <http://portal.mec.gov.br/seesp/arquivos/pdf/lei 8069 02.pdf> Acesso em: 10 ago. 2016.

BRASIL. Lei de Diretrizes e Bases da Educação Nacional (LDB), Lei no 9.394, de 20 de dezembro de 1996. Disponível em:

http://www.planalto.gov.br/ccivil 03/Leis/L9394. htm>. Acesso em: 10 ago. 2016.

BRASIL. Ministério da Educação e do Desporto. Secretaria de Educação Fundamental. Referencial curricular nacional para a educação infantil. Brasília: MEC/SEF, 1998. v. 1-3. CONTRERAS-DOMINGO, J. ¿Como se hace? Cuadernos de Pedagogia, Barcelona, n. 224, p. 14-19, abr. 1994.

LIMA, J. M. L.; LIMA, M. R. C. A ludicidade como eixo das culturas da infância. Interacções, n. 27, p. 207-231, 2013. Disponível em:

http://revistas.rcaap.pt/interaccoes/article/down load/3409/2724. Acesso em 10 ago. 2016.

MULLER, F. Infância em perspectiva: políticas, pesquisas e instituições. São Paulo: Cortez, 2010. 255 p.

SARMENTO, M. J. As culturas da infância nas encruzilhadas da 2 a modernidade. In SARMENTO, M. J.; CERISARA, A. B. (Org.). Crianças e miúdos: perspectivas sociopedagógicas da infância e educação. Lisboa: ASA, 2004.

ONU. Declaração Universal dos Direitos da

Criança. 1959. Disponível em

http://bvsms.saude.gov.br/bvs/publicacoes/decla racao universal direitos crianca.pdf. Acesso em 25/08/2016.

SILVA, E. L.; MENEZES, E. M. Metodologia da pesquisa e elaboração de dissertação. 4. Ed. rev. atual. - - Florianópolis: UFSC, 2005. 138 p.

Recebido para publicação em 30/08/2016

Revisado em 12/09/2016

Aceito em 16/09/2016 